\section{UNIVERSITY OF LONDON.}

BACHELOR OF MEDICINE.-FIRST EXAMINATION, 1843. EXAMINATION FOR HONORS.

[The names are arranged in the order of proficiency.] Anatomy and Physiology.

Jackson, Alfred (exhibition and gold medal), Univer. sity College.

Jemmett, Benjamin Lancaster (gold medal), King's College.

Hakes, James, University College.

Redfern, Peter, Queen's College, Edirburgh.

Eyre, Benjamin Magor, University College.

Littleton, Nicholas Henry, University College.

Chemistry.

Hakes, James (exhibition and gold medal), University College.

Jemmett, Benjamin Lancaster, King's College.

Littleton, Nicholas Henry, University College. Materia Medica and Pharmaceutical Chemistry.

Hakes, James (exhibition and gold medal), University College.

Redfern, Peter (gold medal), Queen's College, Edinburgh.

Jemmett, Benjamin Lancaster, King's College.

Jackson, Alfred, University College.

Littleton, Nicholas Henry, University College.

\section{ROYAL COLLEGE OF SURGEONS IN LONDON.}

Members admitted Friday, August 18, 1843.

H. S. Wharton, E. H. Ambler, J. A. Poole, J. T. S. Jolley, W. F. Coles, D. Davies, J. Beedell, P. Redfern, B. S. Tallan, C. M. Wayte.

\section{BOOKS RECEIVED.}

Facts and Observations relative to the Influence of Manufactures upon Health and Life. By Daniel Noble, M.R.C.S., \&c. \&c. London : Churchill, 1843. pp. 81.

On the Arrangement and Nomenclature of Mental Disorders. By Henry Johnson, M.D., Edin. pp. 33.

\section{TO CORRESPONDENTS.}

We cannot publish the letter of Dr. Edward Johnson on hydropathy, which has already appeared in the "Morning Post."

Dr. Moris's paper on spinal irritation has been received, and shall appear as soon as we can make room for it.

An Aspirant (Bath).-The College of Physicians have no right to grant degrees in medicine, and their newly-created extras have no right to the title of Dr., at least arising from their connection with the college. The whole affair is a gross money job, and nothing less.

Communications have been received from Mr. Fletcher, Shiffnal; Dr. Favell, Sheftield; Mr. Smart, Cranbourne.

\section{ERRATA.}

We are requested to notice the following errata in Mr. Copeman's paper, contained in No. 150:-At page 405 , col. 1, line 35 , for " ammonia," read potash; at col. 2, line 20, for "arterialisation," read imperfect arterialisation.

In last Number, page 430, col. 2, line 25, for "on," read or ; line 29, for "Wurzel," read Wenzel.
MEDICAL.

70 BE DISPOSED OF, an old-established PRACTICE in a City in the West of England, to which is attached several Public Appointments. A good and sufficient introduction will be given, to ensure the connection. To any Gentleman of active and regular habits, it presents an opportunity of no ordinary character. Principals only will be treated with.

Address (prepaid), A. Z., Post-office, Bath.

DR. MARTIN H. LYNCH'S NEW VAPOR BATH.

J. MORRIS, IRONMONGER and MANUFACTURER of WARM VAPOR and SHOWER BATHS, begs leave respectfully to inform Gentlemen of the Medical Profession, and especially the Members of the Provincial Medical and Surgical Association, that he is now prepared to forward the above useful and simple Apparatus in Copper and Tin, including Dr. Lynch's recently in. vented Diffuser, by which the foot-bath is dispensed with, the entire supply of vapor being conveyed through the Diffuser, which forms a footstool, and by means of which the great desideratum in such baths is com. pletely achieved-namely, the production of perspiration in the feet as profuse as in the neck and chest. PRICES FOR CASH: $£$ s. $d$.

Strong Tin Boiler and Pipes, with Stand and Lamp, Diffuser, and Packing-case . . $017 \quad 0 \quad 0$ Copper Boiler and Pipes, with Stand and

Lamp, Diffuser, and Box, with Lock, \&c. 110

Fine Canvas Cloak ............. 1 00

Portable Stool, with Eight Shifting Legs and

Hoop, Brass Fastenings, and Thumb

Screws, \&c. ................... 018

C. J. Morris, 32, Parliament-street.

NEW A PARATUS AND BANDAGES,-WEISS and SON beg to recommend Dr. Hull's 'Abdominal Supporter for Prolapsus Uteri, which, after many years' experience, has been universally approved of, and found to supersede every form of pessary. It is applied externally, and affords immediate relief, enabling those previously confined to a recumbent position to walk about with ease and comfort, while in many instances a cure has been effected.

$*_{*}^{*}$ For the convenience of Ladies, Werss and Son have a private establishment, at 9 , King Williamstreet, Strand, where the Supporters, and every other description of Surgical Apparatus and Bandages, Syringes, \&c., may be obtained. It is conducted by Mrs. Seltzer, who has had long experience in their business, and who will attend Ladies at their own houses, where required.

Pamphlets and Supporters may be had at their house, 62, Strand, or of Mrs. Higham, 48, Jermyn-st.

Elastic Kaitted Surgical Bandage.-This new and improved fabric will be found to give equal support, and to be less heating, than the Cotton Bandage usually employed. A more common sort is manufactured for the use of Hospitals, and a very fine description for those patients whose skin is delicate.

Duval's Steam and Hot-Air Apparatus, as used at Guy's Hospital.- This very useful Apparatus will be found exceedingly portable and convenient for hospital use or private practice, for the local applica tion of steam, for a steam or hot-air bath, and for a sulphur or medicated vapour bath. It has been ex tensively used in Paris, and a translation of the report of the Royal Medical Academy, with plates and descriptions, may be had upon application.

Agents for the sale of the above, and for Weiss's Instruments, on the same terms as in London:Dublin: Fannin and Co. Cork: Edwards Casey. Edinburgh: William Pugh. Aberdeen: Charles Davidson. Manchester: L. Simpson. Birmingham: T. Flewitt. 